\title{
Erratum to: Bioequivalence and Tolerability Assessment of a Novel Intravenous Ciclosporin Lipid Emulsion Compared to Branded Ciclosporin in Cremophor ${ }^{\circledR}$ EL
}

\author{
Karl Henrik Johannes Ehinger • Magnus Joakim Hansson • \\ Fredrik Sjövall · Eskil Elmér
}

Published online: 8 January 2013

(C) Springer International Publishing Switzerland 2013

\section{Erratum to: Clin Drug Investig \\ DOI 10.1007/s40261-012-0029-x}

\begin{abstract}
A Published-Ahead-of-Print version of this article was made available online at http://adisonline.com/druginvest igation/toc/publishahead on 28 November 2012. An error was subsequently identified in that version of the article, and the following correction should be noted:
\end{abstract}

Section 4, paragraph 6, line 4, which previously read:

"Ciclosporin ${ }^{\circledR}$ is currently being investigated as pharmacological therapy in patients undergoing intervention treatment after myocardial infarction (the CIRCUS Phase III study, "Cyclosporine and Prognosis in Acute Myocardial Infarction [MI] Patients", clinicaltrials.gov identifier NCT01502774)."

Should read:

"CicloMulsion ${ }^{\circledR}$ is currently being investigated as pharmacological therapy in patients undergoing intervention treatment after myocardial infarction (the CIRCUS Phase III study, "Cyclosporine and Prognosis in Acute Myocardial Infarction [MI] Patients", clinicaltrials.gov identifier NCT01502774)."

The online version of the original article can be found under doi:10.1007/s40261-012-0029-x.

K. H. J. Ehinger $(\bowtie) \cdot$ M. J. Hansson · F. Sjövall · E. Elmér NeuroVive Pharmaceutical AB (publ), Medicon Village,

22381 Lund, Sweden

e-mail: johannes.ehinger@neurovive.com

K. H. J. Ehinger · M. J. Hansson · F. Sjövall · E. Elmér Mitochondrial Pathophysiology Unit, Department of Clinical

Sciences, Lund University, Lund, Sweden 